\title{
A Study of the Interface of Soldered Joints of SnlnAgTi Active Solder with Ito Ceramics
}

\author{
M. Provazník, R. Koleňák
}

\begin{abstract}
This paper presents an analysis of the solderability ITO ceramics $\left(\operatorname{In}_{2} \mathrm{O}_{3} / \mathrm{SnO}_{2}\right)$. The soft active solder SnInAgeTi was used for the experiments. The solder was activated by power ultrasound in air without flux. An analysis of the interface of the phases between the solder and the ceramic was carried out in order to discover the ultrasonic impacts on the active metal and to identify the mechanism of the joint on the ceramic side.
\end{abstract}

Keywords: ultrasonic activation, active solder, ITO (indium-tin oxide) ceramics.

\section{Introduction}

Ceramic materials are increasingly used in technical practice, especially in the field of electrotechnology. There is enormous demand for conductive joining of ceramics with metals. Soldering with the use of active solders is a current trend in this area. These solders contain an active element which reacts with the surface of the ceramic material. This enables it to be wetted and a reaction layer created. The solders have a very low wetting angle, enabling soldering at low temperatures, without flux and additional protection.

The most widely used active metal is titanium. The reactive product transforms the surface energy of ceramics and enables wetting of the solder. The active element moves from the whole solder volume to the two soldered materials. At the interface of the soldered joint, a reaction layer several $\mu \mathrm{m}$ in thickness is created, which contains the reaction products of the active elements and the substrate [1].

The solder is activated mechanically or with the use of a very high temperature to influence the active element. The mechanical application is achieved by scraping, by spreading with a metal brush (soldering $\mathrm{Cu}, \mathrm{Al}$, or $\mathrm{CrNi}$ steel), by vibration, or by ultrasound above $20 \mathrm{kHz}$ (soldering ceramics and non-metallic materials). The working cycle of the mechanical application is approximately 10 times shorter than high temperature activation, and does not require the application of a vacuum or a protective atmosphere.

\section{Experiments}

A sample was made using the apparatus shown in Fig. 1. The soldering process involves heating the soldered materials with the use of a hot plate to the soldering temperature in the range of $150-160{ }^{\circ} \mathrm{C}$. The maximum soldering temperature is limited to $160^{\circ} \mathrm{C}$, when surface oxidation of ITO ceramics increases. Heating by steps is chosen in order to achieve steady heating of both materials. A strap-shaped solder made by fast cooling technology is placed on a heated substrate, see Fig. 2. The solder is activated by a titanium peak of the ultrasonic equipment after melt-down. The activation time was chosen in the interval from 1 to 5 seconds in one contact point. Tab. 1 presents the parameters of the US equipment. The solder is applied to the second substrate in the same way. The two prepared parts are joined and softly pushed. The presence of the active solder protects the high plasticity of the phase interface.

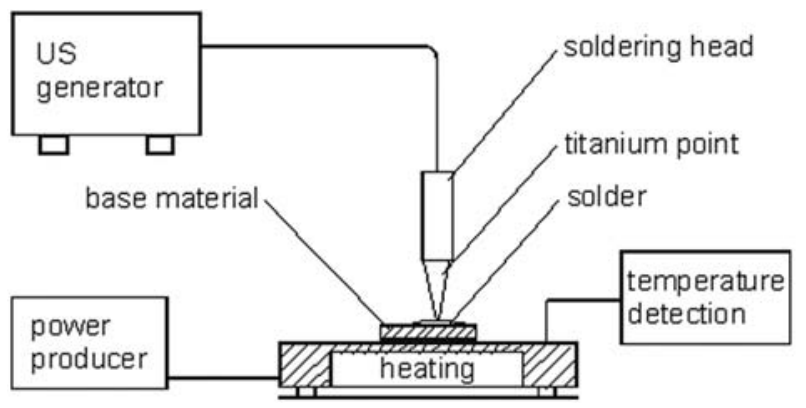

Fig. 1: Diagram of the apparatus for soldering by ultrasound

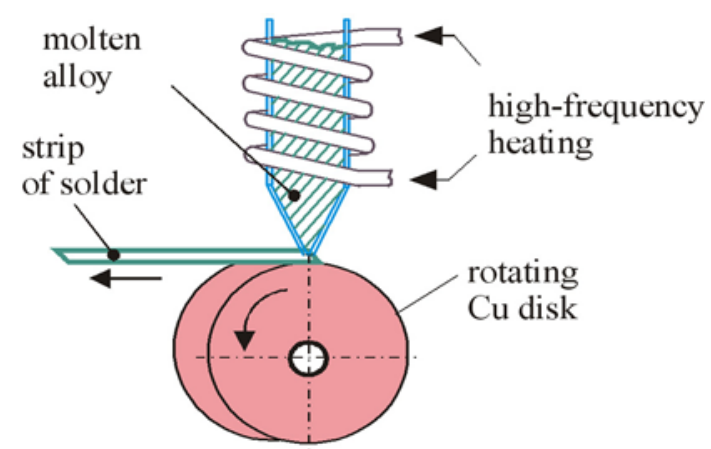

Fig. 2: Solder production by fast cooling technology [2] 
Table 1: US equipment parameters

\begin{tabular}{|l|c|l|}
\hline $\begin{array}{l}\text { Output power }- \\
\text { intermittent service }\end{array}$ & {$[\mathrm{W}]$} & $\max .400$ \\
\hline Operative frequency & {$[\mathrm{kHz}]$} & 40 \\
\hline Input power & {$[\mathrm{W}]$} & $\max .600$ \\
\hline Time adjustment range & {$[\mathrm{s}]$} & $0.1-9.9$ for 0.01 \\
\hline
\end{tabular}

The soldering samples were fixed after splitting, and were prepared using a standard metallographic methodology. The samples were then analyzed using a light microscope and a scanning electron microscope. For further documentation of the joint creation mechanism, rtg. diffraction analysis was used for analyzing the concentration profiles of each element.

Production principle of the active solder foil

1. The molten alloy is extruded by fine pressure of an inert gas (argon, helium) through the rectangular slot of a jet placed near the cooling disk.

2. The rotating cooling disk gradually touches the molten solder. The disk creates a thin layer of solid alloy which the roller takes away.

The solder in foil shape with parameters $0.15 \mathrm{~mm} \times 7 \mathrm{~mm}$ was made by the SAV Physical Institute, Bratislava for experimental purposes. The solder was made from foundry alloy by ready casting in an ingot mould.

\section{Experiment results}

A differential thermic analysis was made on a sample of active solder. The process of this analysis is recorded in Fig. 3. Using the DTA graphs we can specify the thermal areas where there are phasic metamorphoses. A temperature of $116{ }^{\circ} \mathrm{C}$ characterizes the onset of molten eutectic Sn-In. A temperature of $156{ }^{\circ} \mathrm{C}$ is the molten temperature of neat indium.

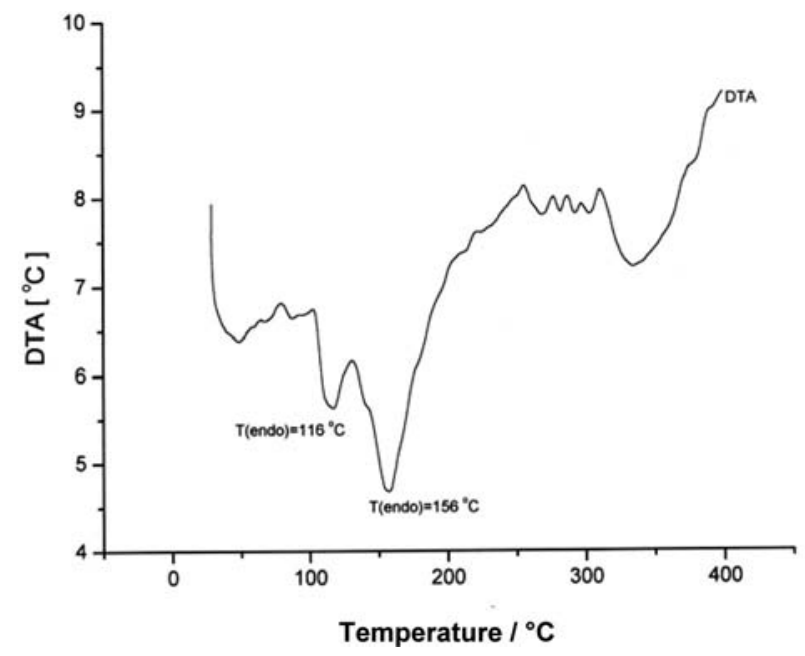

Fig. 3: DTA of SnInAgTi solder

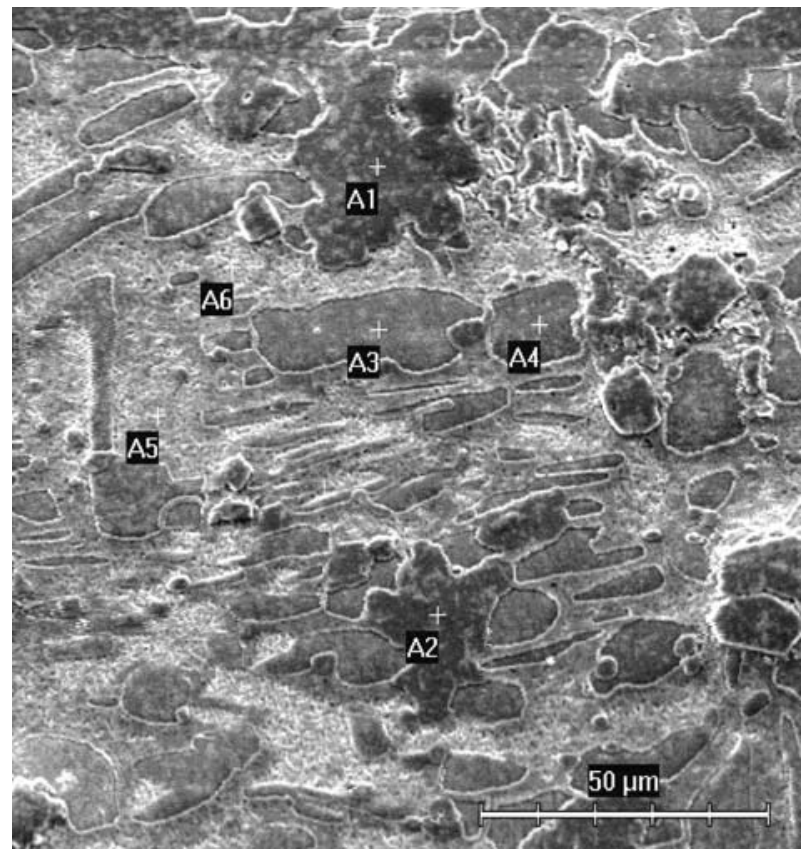

Fig. 4: Microstructure of SnInAgTi active solder [3]

Fig. 4 presents the heterogeneous microstructure of the SnInAgTi soft active solder in the molten state.

A quantitative chemical analysis of the solder, shown in Fig. 4, is described in Tab. 2. The dark grains, specified as positions A1 and A2, are expressively enriched with $\mathrm{Ti}$ and $\mathrm{Ag}$. Other pallid grains (areas A3, A4) and the matrix (position A5, A6) are explicitly composed of In and Sn elements.

Table 2: Quantitative analysis of SnInAgTi solder [3]

\begin{tabular}{|c|c|c|c|c|}
\hline & $\begin{array}{c}\mathrm{Ti} \\
\text { [at. \%] }\end{array}$ & $\begin{array}{c}\mathrm{Ag} \\
\text { [at. \%] }\end{array}$ & $\begin{array}{c}\mathrm{In} \\
\text { [at. \%] }\end{array}$ & $\begin{array}{c}\mathrm{Sn} \\
\text { [at. \%] }\end{array}$ \\
\hline A1 & 3.1 & 27.6 & 55.1 & 14.3 \\
\hline A2 & 1.9 & 29.3 & 53.0 & 15.8 \\
\hline A3 & 0 & 0.3 & 11.3 & 88.5 \\
\hline A4 & 0 & 0 & 12.1 & 87.9 \\
\hline A5 & 2.7 & 0 & 64.7 & 32.7 \\
\hline A6 & 0 & 0 & 71.4 & 28.7 \\
\hline
\end{tabular}

In order to identify the phasic composition of the solder after moulding, a radiographic diffraction analysis was made by the SAV Physical Institute, Bratislava, which identified the following phases: $\mathrm{In}_{3} \mathrm{Sn}, \mathrm{InSn}_{4}, \mathrm{Ti}_{6} \mathrm{Sn}_{5}, \mathrm{Ag}_{3} \mathrm{Sn}, \mathrm{AgIn}_{2}, \mathrm{Ti}_{3} \mathrm{Ag}$ [3]. We can identify the dark areas of the solder as the $\mathrm{Ti}_{3} \mathrm{Ag}$ phase, which demonstrates the high affinity of titanium to silver.

Fig. 5 shows the phasic interface of solder and ITO ceramics. The concentration profiles of the individual elements across the interface demonstrate that $\mathrm{Ti}$ participates in the creation of the joint, but 

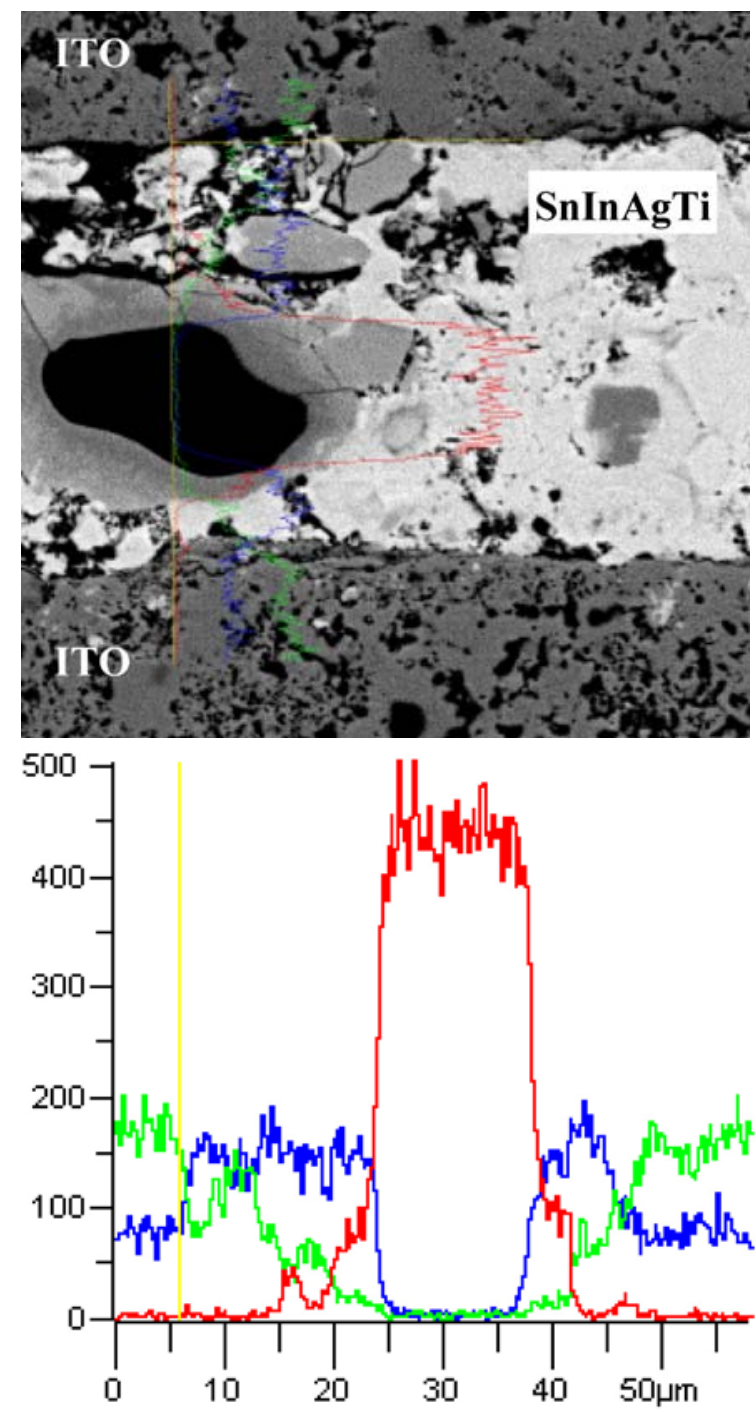

Titanium Ka1, Indium La1, Tin La1
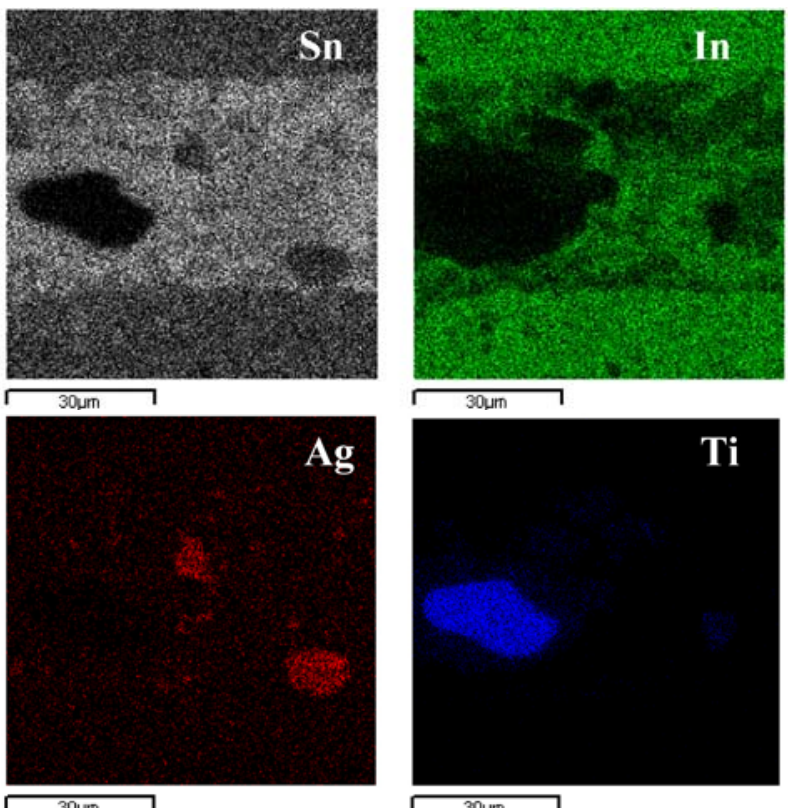

Fig. 5: The SnInAgTi - ITO interface, and the concentration profiles of the individual elements over the interface it is supposed that Indium has the greatest effect on the creation of the joint. A provable effect of power ultrasound is that the solder is able to fill the narrow spaces among the ceramic grains, proving that there is a high degree of ceramic wetting when soldering is performed.

Indium markedly supports the creation of the joint at this monitoring interface. The experiments show clearly that the mission of an active element in solder does not always have to appear. In this case, the $\mathrm{Ti}$ is indifferent (it does not create any provable phases). It remains fixed in the solder (mainly in the $\mathrm{Ti}_{3} \mathrm{Ag}$ phase) and it does not participate markedly in creating the joint.

Since indium has a high affinity to oxygen, we can assume that it combines in the soldering process with atmospheric oxygen with complex oxide genesis of indium, which provides an input into the reactions with the surface of the ITO ceramics by the simplified model shown in Fig. 6.

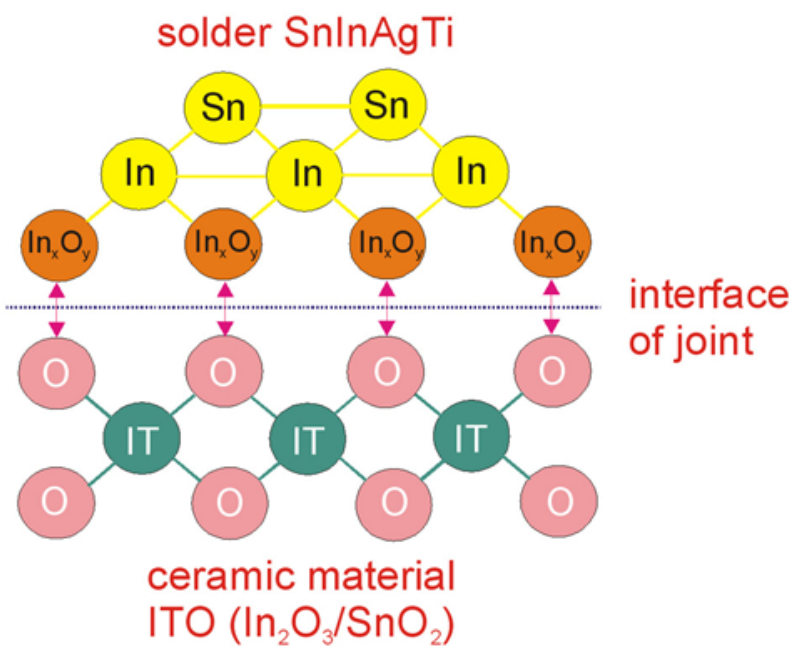

Fig. 6: Simplified model of the creation of the joint between ITO ceramics and SnInAgTi solder [4]

\section{Our contribution to new findings}

Our contribution to work on this topic can be summarized as follows:

- a soft active SnInAgTi solder has been designed and manufactured by methods of fast cooling,

- our analyses of the phase structure of the solder has identified the following phases: $\operatorname{In}_{3} \mathrm{Sn}$, $\mathrm{InSn}_{4}, \mathrm{Ti}_{6} \mathrm{Sn}_{5}, \mathrm{Ag}_{3} \mathrm{Sn}, \mathrm{AgIn}_{2}, \mathrm{Ti}_{3} \mathrm{Ag}$,

- the SnInAgTi solder drenched ITO ceramics with the use of power ultrasound,

- studies of the interfaces have shown that when a joint with ITO ceramics is created, indium from the solder participates preferentially. 


\section{Conclusion}

The results of our experiments have verified the possibility of creating a soldering joint between a metal and an ITO ceramic. The soldering joint is produced with the use of mechanical activation power ultrasound on air, without flux. It has been proved that an SnInAgTi solder reacts with the surface layers of the connected metals by creating reactive products of various thicknesses and qualities. This proves that the solid substrates dissolve in the solder and create diffusion joints.

There is no evident diffusion area on the interface between the solder and the ITO ceramics. The solder is able to leak into the spaces between the grains, and in this way a mechanical joint is created. Indium plays a major role in creating the joint. Indium creates oxide inputs that react with the ceramics and create a chemical bond.

\section{Acknowledgement}

This paper has been prepared with support from the VEGA 1/0381/08 Project - Research into the Influence of Physical and Metallurgical Aspects of High Temperature Soldering upon the Structure of Metallic and Ceramic Materials' Joints, and the APVT 20-010804 Project — The Development of a Leadfree Soft Active Solder and Research into the Solderability of Metallic and Ceramic Materials using Ultrasonic Activation.

\section{References}

[1] Chang, S. Y., Tsao, L. C., Chiang1, M. J., Chuang, T. H., Tung, C. N.: Active soldering of indium tin oxide (ITO) with $\mathrm{Cu}$ in air using an $\mathrm{Sn3.5Ag4Ti(Ce,} \mathrm{Ga)} \mathrm{filler,} \mathrm{Journal} \mathrm{of} \mathrm{Mate-}$ rials Engineering and Performance, 2003, No. 4, pp. 383-389.

[2] Koleňák, R.: Solderability of metal and ceramic materials by active solders. 1st ed. Dresden, Forschungszentrum Dresden, 2008. (Scientific monographs). ISBN 978-3-941405-03-5.

[3] Adamčíková, A.: Study of ceramics wetting by lead-free solders, Master's thesis, 2007.

[4] Koleňák, R: The Development of a Lead-free Soft Active Solder and Research into the Solderability of Metallic and Ceramic Materials using Ultrasonic Activation, Final report of grant project APVT 20-010804. Trnava, 2008.

Ing. Martin Provazník

E-mail: martin.provaznik@stuba.sk Institute of Production Technologies MTF STU, Trnava, Slovak Republic

doc. Ing. Roman Koleňák, PhD.

E-mail: roman.kolenak@stuba.sk

Institute of Production Technologies MTF STU, Trnava, Slovak Republic 